Research Article

\title{
A Quasi Experimental Study to Assess the Effectiveness of Nipple Stimulation in the Progress of Labour among Primipara Women during First Stage of Labour in Selected Hospital of Jabalpur (M.P.)
}

\author{
Vinitha Suresh', Rajni Soni
}

${ }^{1}$ Professor and Head of Department (Obstetrics and Gynaecology Nursing), Jabalpur Institute of Nursing Sciences and Research, Jabalpur, Madhya Pradesh, India.

${ }^{2}$ Assistant Professor, Bhagyodaya College of Nursing, Sagar, Madhya Pradesh, India.

DOI: https://doi.org/10.24321/2348.2133.201901

I $\mathbf{N}$ F $\mathbf{O}$

Corresponding Author:

Vinitha Suresh, Department (Obstetrics and Gynaecology Nursing), Jabalpur Institute of Nursing Sciences and Research, Jabalpur, Madhya Pradesh, India.

E-mail Id:

sureshvinitha02@gmail.com

Orcid Id:

https://orcid.org/0000-0001-9249-7138

How to cite this article:

Suresh V, Soni R. A Quasi Experimental Study to Assess the Effectiveness of Nipple Stimulation in the Progress of Labour among Primipara Women during First Stage of Labour in Selected Hospital of Jabalpur (M.P.). Ind J Holist Nurs 2019; 10(1): 1-7.

Date of Submission: 2019-08-29

Date of Acceptance: 2019-11-15

\section{$\begin{array}{llllllllllllll}\mathbf{A} & \mathbf{B} & \mathbf{S} & \mathbf{T} & \mathbf{R} & \mathbf{A} & \mathbf{C} & \mathbf{T}\end{array}$}

Background: Cost effective and benefit equations are important in health care. When discussing alternative options of care nipple stimulation can be a standardised methodology for induction of labour. In accordance to it, a quasi-experimental post-test only control group design, was carried out in selected hospitals in Jabalpur city to assess the effect of nipple stimulation. The basic purpose was to use nipple stimulation as a means of labour induction allowing greater control by mothers and has an advantage of being natural, inexpensive and non-invasive.

Methods: Purposive sampling technique was used for study. 60 subjects were divided into two groups: control and experimental, each group 30 sample (primipara women). The experimental group was given nipple stimulation for $15 \mathrm{~min}$ alternatively during active phase. The result was determined by modified BISHOPS SCORE and DURATION of active stage of labour (4-7cm dilatation).

Results: The principle result findings stated that, modified BISHOP score was satisfactory is $23(76.6 \%)$ in control group and $27(90 \%)$ in experimental group. Partially satisfactory were 7 (23.4\%) in control group and $3(10 \%)$ in experimental group and none not satisfactory. The duration of labour in control group came to be $12(40 \%)$ subjects had frequency less than $4 \mathrm{hrs}$ and $18(60 \%)$ had had duration more than $4 \mathrm{hrs}$. whereas in experimental group 19(64.3\%) had duration less than $4 \mathrm{hrs}$ and only $11(36.6 \%)$ had duration more $4 \mathrm{hrs}$. The effectiveness of nipple stimulation in experimental group was statistically proved by $t$ test.

Conclusion: Hence it could be concluded than, nipple stimulation was effective in early effacement and dilatation of cervix during first stage of labour in active phase among primipara women.

Keywords: Nipple Stimulation, Progress of Labour, Primipara Women, First Stage of Labour

Indian Journal of Holistic Nursing (ISSN: 2348-2133) 


\section{Introduction}

Nipple stimulation has been suggested as an effective inexpensive non-medical means of inducing labour. Nipple stimulation is a natural way that mothers in labour can speed up progress. Mothers in labour, who are progressing slowly, can gently pull or have their partner gently suckle on their nipples. The stimulation of the nipple's releases oxytocin, the hormone that causes the uterus to contract, according to Birthing Naturally. Nipple stimulation is the gentle rubbing or rolling of the nipple to encourage the start of contractions. The theory is that oxytocin, a hormone that causes contractions, is released in the body when the breasts are stimulated. ${ }^{4}$

Oxytocin is a hormone released from the posterior pituitary gland and it is released in a pulsed manner in response to stimulation. It is a cost-benefit alternative and an effective method for induction and augmentation of labour. ${ }^{1}$

\section{Need of the Study}

Nipple stimulation has been suggested as an effective means of inducing labour. It is both an inexpensive and non-medical intervention which allows women greater control over the induction process. Nipple stimulation has been shown to be effective for contraction stress tests and for the augmentation of labour. This is one of a series of reviews of methods of cervical ripening and labour induction using a standardised methodology. ${ }^{5}$

Nipple stimulation can also be used for augmentation of uterine activity in case of hypotonic uterine action. Breast stimulation as a means of labour induction allows women greater control over the induction process and has the advantage of being natural and inexpensive non-medical methods. ${ }^{5}$

\section{Objectives}

- Assess the progress of labour among Primipara mothers in control group.

- Assess the progress of labour among Primipara mothers in experimental group.

- Assess the effectiveness of nipple stimulation in progress of labour in control group and after giving intervention in experimental group.

- Associate the progress of labour with their selected socio demographic variables in control group.

- Associate the progress of labour with their selected socio demographic variables in experimental group.

\section{Operational Definition}

\section{Nipple Stimulation}

- It is the rolling the nipple back and forth with thumb and forefinger will cause the release of oxytocin from the posterior pituitary gland. This will have effect of stimulating contractions (Figure 1).

- The criteria of nipple stimulation only one breast stimulate at a time for $10 \mathrm{~min}$ with $5 \mathrm{~min}$ interval and repeat the procedure with another breast.

- Wait for about $15 \mathrm{~min}$ to see if the uterus begins to contract. If contraction doesn't start, repeat the steps. If contraction occurs don't stimulate the nipple during contraction. Stop doing nipple stimulation when contractions are close together and a min apart.

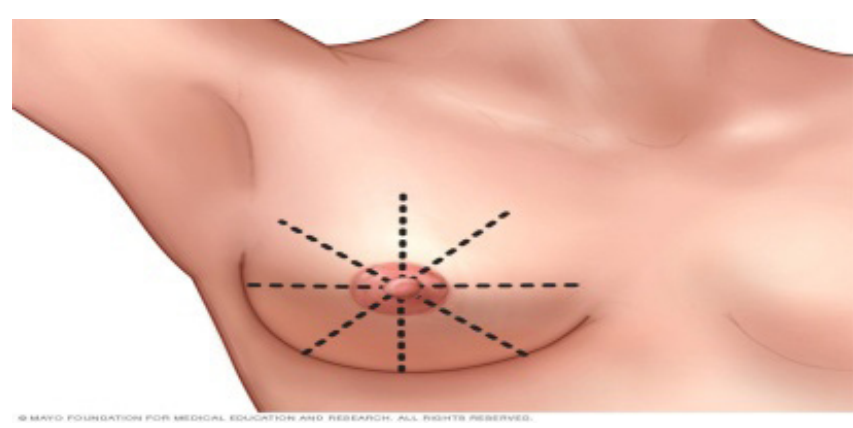

Figure I.Nipple stimulation and contraction radiation Hypothesis (All Hypothesis were tested at the $\mathbf{0 . 0 5}$ level of significance)

$\mathbf{H}_{1}$ : There will be a significant difference in progress of labour among primipara women in control group and experimental.

$\mathrm{H}_{2}$ : There will be a significant association between the progress of labour with selected socio demographic variables in control group.

$\mathbf{H}_{3}$ : There will be a significant association between the progress of labour with selected socio demographic variables in experimental group.

\section{Methods}

A quantitative \& evaluative research approach was used in the study. Non-probability purposive sampling technique was used in the study. In this study, quasi experimental post-test only control group design was used. This study is proposed to be conducted in selected hospitals Jabalpur.

Sample consisted of 60 primipara women. 30 women were in experimental group and 30 women was assign in control group. Duration of the study was 8 months from February 2018 to September 2018. Data collection period was from $1^{\text {st }}-30$ June 2018.

In this study, Primipara women in the first stage of labour was used as population. Primipara women in first stage of labor (Active Phase $4 \mathrm{~cm}$ to $7 \mathrm{~cm}$ cervical dilatation) admitted in labour room at selected hospitals of Jabalpur. In the present study, the sample is the primipara women who fulfilled the inclusion criteria. 


\section{Criteria for Selection of the Sample Inclusion Criteria}

Women who were:

- $\quad$ Primipara with completion of 37 weeks of gestation.

- In first stage of labour with $4 \mathrm{~cm}$ to $7 \mathrm{~cm}$ dilation of the cervix.

- Willing to participate.

- Who undergoes normal vaginal delivery.

\section{Exclusion Criteria}

Women who were:

- Having complications for normal vaginal delivery.

- Having high risk pregnancy.

- Seriously ill and tired.

- On oxytocin infusion and prostaglandin gel or tablet application.

\section{Validation of Tools}

Validation of the tool was done by 13 experts of obstetrics and gynae department except some modifications in the socio-demographic data no major corrections were there in the tool.

\section{Reliability}

The reliability of the tool was determined by the interrater method and was 0.87 .

\section{Data Collection Tools}

- Section A: Socio-demographic profile it includes age, educational status of mother, occupation, socioeconomic status and assess the labour pain intensity during labour pain.

- Section B: Clinical tools include the height, weight, age of menarche, haemoglobin level, and admission criteria in the hospital.

- Section C: Assess the progress of labour through partograph every 15 minutes.

- Section D: Assess the effacement and dilatation of the cervix through Bishop's Score.

Table I.Modified Bishop Score

\begin{tabular}{|c|c|c|c|c|c|}
\hline \multirow{2}{*}{ Parameter } & \multicolumn{4}{|c|}{ Scores } & \multirow[t]{2}{*}{ Scoring } \\
\hline & 0 & 1 & 2 & 3 & \\
\hline Position & Posterior & middle & anterior & - & \\
\hline Consistency & Firm & Medium & Soft & - & \\
\hline Effacement & $0-30 \%$ & $40-50 \%$ & $60-70 \%$ & $80+\%$ & \\
\hline Dilation & Closed & $1-2 \mathrm{~cm}$ & $3-4 \mathrm{~cm}$ & $5+\mathrm{cm}$ & \\
\hline Fetal station & -3 & -2 & $-1,0$ & $+1,+2$ & \\
\hline & & & & Total & \\
\hline
\end{tabular}

Table 2.Score interpretation

\begin{tabular}{|c|c|}
\hline \multicolumn{2}{|c|}{ Scoring Interpretation } \\
\hline Scores & Remark \\
\hline $8-13$ & Good normal vaginal delivery \\
\hline $6-7$ & Partially chances of normal delivery \\
\hline$<5$ & Not satisfactory/ normal vaginal delivery is not possible \\
\hline
\end{tabular}

\section{Results}

Table 3.Progress of labour in control group and experimental group, the time duration of active stage of labour

$(\mathrm{N}=60)$

\begin{tabular}{|c|c|c|c|c|}
\hline & $\begin{array}{c}\text { <4-hour frequency } \\
\text { (n) }\end{array}$ & $\begin{array}{c}\text { Percentage } \\
\text { (\%) }\end{array}$ & $\begin{array}{c}\text { >4-hour Frequency } \\
\text { (n) }\end{array}$ & $\begin{array}{c}\text { Percentage } \\
\text { (\%) }\end{array}$ \\
\hline Control group & 12 & 40 & 18 & 60 \\
\hline Experimental group & 19 & 63.4 & 11 & 36.6 \\
\hline
\end{tabular}




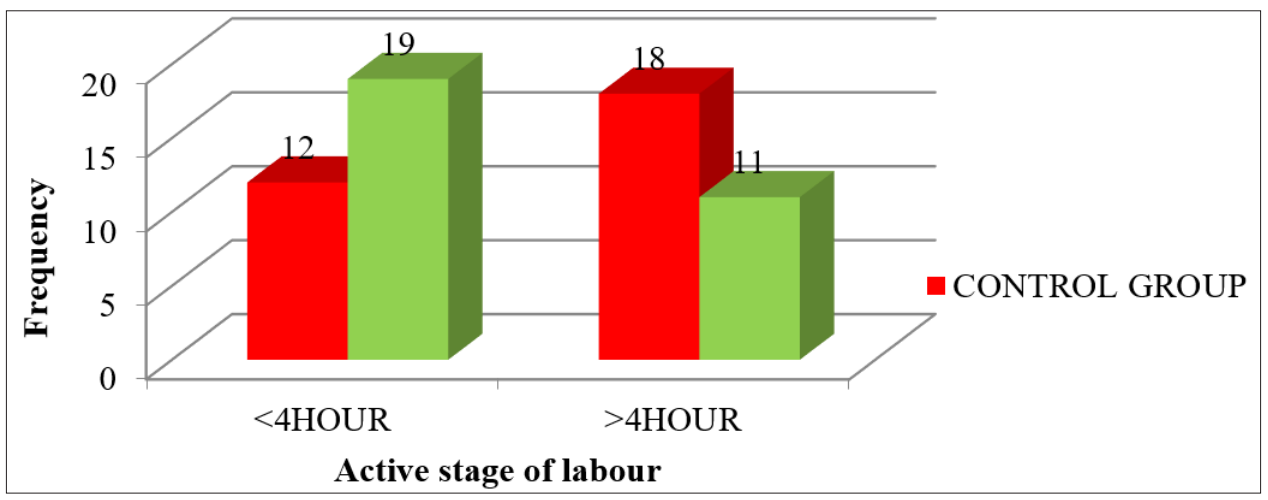

Figure 2.Time duration of active stage of labour in control group\& experimental group

Table 4.Time duration of active stage of labour in control group\& after implementation of nipple stimulation in experimental group

\begin{tabular}{|c|c|c|c|c|c|c|}
\hline S. No. & Description & Mean & Mean difference & SD & SD Difference & t-value \\
\hline 1. & Control group & 12.44 & \multirow{2}{*}{3.71} & 3.56 & \multirow{2}{*}{0.4} & \multirow{2}{*}{4.26} \\
\hline 2. & Experimental group & 16.15 & & 3.16 & & \\
\hline
\end{tabular}

Value=2.0010; significant at $0.05 \%$ level of significance.

Hence, it is proved that nipple stimulation plays an effective role in early effacement and dilatation of cervix during active stage $(4-7 \mathrm{~cm})$ of labour.

Analysis of Dilatation and Effacement of the Cervix in Primipara Women in First Stage of Labour Control Group

Table 5.Interpretation of Bishop's Score

\begin{tabular}{|c|c|c|}
\hline $\begin{array}{c}\text { Interpretation of } \\
\text { variable in bishop } \\
\text { score }\end{array}$ & $\begin{array}{c}\text { Frequency } \\
\text { (n) }\end{array}$ & $\begin{array}{c}\text { Percentage } \\
\text { (\%) }\end{array}$ \\
\hline Satisfactory & 23 & 76.6 \\
\hline Partially satisfactory & 7 & 23.4 \\
\hline Not satisfactory & 0 & nil \\
\hline
\end{tabular}

Interpretation of the variables in bishop score shows the analysis of bishop score in control group in which the maximum scoring is in satisfactory that is $23(76.6 \%)$ and 7 were in partially satisfactory and none were in not satisfactory.

Analysis of Dilatation and Effacement of the Cervix in Primipara Women in First Stage of Labour in Experimental Group

Table 6.Bishops score of experimental group

\begin{tabular}{|c|c|c|}
\hline $\begin{array}{c}\text { Interpretation of } \\
\text { variable in bishop score }\end{array}$ & $\begin{array}{c}\text { Frequency } \\
\text { (n) }\end{array}$ & $\begin{array}{c}\text { Percentage } \\
\text { (\%) }\end{array}$ \\
\hline Satisfactory & 27 & 90 \\
\hline Partially satisfactory & 3 & 10 \\
\hline Not satisfactory & 0 & nil \\
\hline
\end{tabular}

Bishop score of experimental group Shows after giving the intervention of nipple stimulation in Primipara women in first stage of labour in which the maximum scoring in satisfactory 27 (90\%) and partially satisfactory score is 3 $(10 \%)$ and none in not satisfactory.

Table 7.Assess the effectiveness of nipple stimulation in progress of labour in control group \& after intervention in experimental group by modified Bishop's score

$(\mathrm{N}=60)$

\begin{tabular}{|c|c|c|c|c|}
\hline \multirow{2}{*}{$\begin{array}{c}\text { Interpretation of variable in } \\
\text { Bishop score }\end{array}$} & \multicolumn{2}{|c|}{ Control group } & \multicolumn{2}{c|}{ Experimental group } \\
\cline { 2 - 5 } & $\begin{array}{c}\text { Frequency } \\
\text { (n) }\end{array}$ & $\begin{array}{c}\text { Percentage } \\
(\%)\end{array}$ & $\begin{array}{c}\text { Frequency } \\
\text { (n) }\end{array}$ & $\begin{array}{c}\text { Percentage } \\
(\%)\end{array}$ \\
\hline Satisfactory & 23 & 76.6 & 27 & 90 \\
\hline Partially satisfactory & 7 & 23.4 & 3 & 10 \\
\hline Not satisfactory & 0 & 0 & 0 & 0 \\
\hline
\end{tabular}




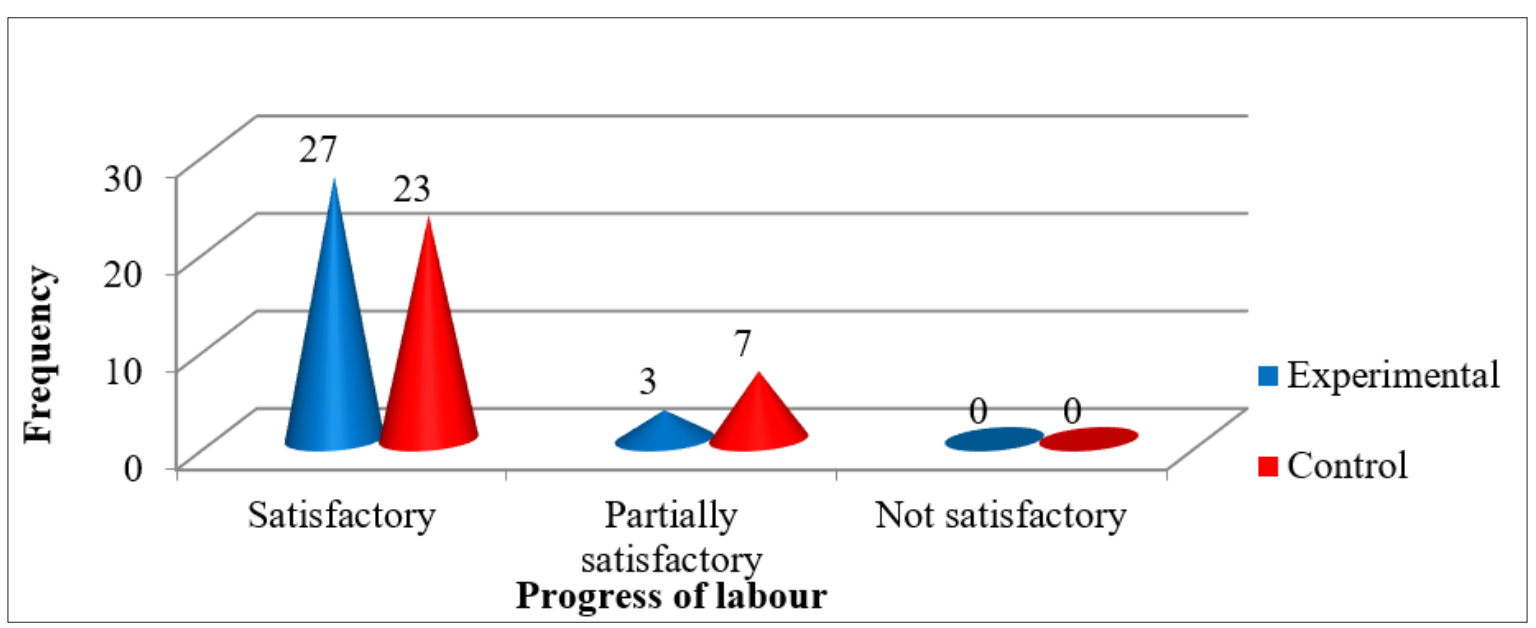

Figure 3.Assess the effectiveness of nipple stimulation in progress of labour in control group \& after intervention in experimental group by Modified Bishop's Score

Table 8.Comparison of control \& experimental group of Modified Bishop Score scale

\begin{tabular}{|c|c|c|c|c|c|c|}
\hline S. No. & Description & Mean & Mean difference & SD & $\begin{array}{c}\text { SD } \\
\text { Difference }\end{array}$ & $t$-value \\
\hline 1. & Control group & 8.83 & \multirow[b]{2}{*}{1.2} & 1.41 & \multirow[b]{2}{*}{0.4} & \multirow[b]{2}{*}{2.926} \\
\hline 2. & Experimental group & 10.03 & & 1.81 & & \\
\hline
\end{tabular}

Table Value $=2.0010$; significant at $0.05 \%$ level of significance.

The t-value was significant at 0.05 , which proved there was significant difference in the progress of labour and that it was better in experimental group after administration of the nipple stimulation in mothers.

Association of Data between The Selected Samples with their Demographic and Clinical Variables of Control Group

- Most Significant: Any menstrual abnormality present.

- Significant: Height of mother, Prior knowledge about nipple stimulation in progress of labor, Educational status, Family income, Types of family, Residential area and Dietary pattern. Others were found to be non-significant.

Association of Data between the Selected Samples with their Demographic and Clinical Variables Experimental Group

- Significant: Number of visits to antenatal clinic, Educational status Others were found to be nonsignificant.

\section{Discussion}

The major interpretation of result findings had a strong background of existing knowledge with supported study findings.
Section I: It dealt with the analyses of progress of labour by plotting the partograph in control group and experimental group after giving the intervention of nipple stimulation

Findings showed that the majority of the analyses of progress of labour by plotting the partograph in control group and experimental group after giving the intervention of nipple stimulation in control group the majority were more than 4 hour that were $18(60 \%)$. And in experimental group the majority were more in less than 4 hour that was 19 (63.4\%).

Salmanym et al., (2007) conducted a study to find out the Breast stimulation for induction of cervical ripening in complicated term pregnancies among 75 mothers. The indications for induction were prolonged pregnancy greater than 42 weeks $(\mathrm{N}=12)$, hypertensive disorders of pregnancy $(\mathrm{N}=26)$, suspected intra-uterine growth retardation $(\mathrm{N}=30)$ and a combination of two or more of the above $(\mathrm{N}=7)$. All patients had a modified Bishop score of less than 5 before the start of nine hours of unilateral breast stimulation spread over three days. Result of the study shows that twenty-nine out of the 75 patients went into labour during the three day period and, of the remainder, there was a significant improvement in the cervical score of $2.87+/$ - 
1.99. Three patients, all of whom had prolonged pregnancy, had exaggerated uterine activity. Two patients had fetal heart rate deceleration on antenatal cardio topography during their first session of breast stimulation but this did not recur in any of their subsequent sessions. No patient had both exaggerated uterine activity and fetal heart rate deceleration. There was no case of perinatal mortality or morbidity.

\section{Section II: It dealt with the analysis of dilatation and effacement of the cervix in primipara women in first stage of labour in experimental group}

Findings showed that the modified Bishop score of experimental group Shows after giving the intervention of nipple stimulation in Primipara women in first stage of labour in which the maximum scoring in satisfactory 27 $(90 \%)$ and partially satisfactory score is $3(10 \%)$ and none in not satisfactory.

Conducted a study to find out the management of Protracted Active Labour with Nipple Stimulation". A Viable Tool for Midwives? The patient is a 36-year-old G3P2 at 39 gestational weeks who presented in labour to the hospital where she planned to give birth. On admission, her initial cervical examination was 2 to $3 \mathrm{~cm}, 100 \%$ effacement, -1 station and membrane intact. She reported regular contractions for 2 hours prior to coming to the hospital. At 12 hours after admission, the midwife suggested Nipple Stimulation in an effort to enhance uterine forces and promote progressive cervical change. ${ }^{6}$

Josieltenore MD, (2009) conducted a comparative study to evaluates breast stimulation and oxytocin infusion as methods for cervical ripening among 40 in patients. Forty patients with a Bishop score of 5 or 6 were randomly selected for either breast stimulation or oxytocin infusion. In a similar group of 20 cases, no method was employed. The samples were divided into two groups. Result showed that the Bishop score improved in $41.2 \%$ of breast stimulation cases. The breast stimulation is effective in ripening the cervix.

\section{Section III: Assess the effectiveness of nipple stimulation in progress of labour in both groups}

Findings showed the comparison between the control group and after application of nipple stimulation in experimental group of modified BISHOP score. In which the satisfactory is $23(76.6 \%)$ in control group and $27(90 \%)$ in experimental group. Partially satisfactory were $7(23.4 \%)$ in control group and $3(10 \%)$ in experimental group and non-was in not satisfactory. $\mathrm{t}=2.926$ that is significant .Data presented that the mean score in the control group without application of nipple stimulation was 8.83 and standard deviation was 1.41. In result of experimental group application of application of nipple stimulation means score was 10.03 and standard deviation was 1.81. In this case the calculated value of $t$ is more than the table value (2.0010), that is 2.926 so this indicated that the nipple stimulation was effective in early effacement and dilatation of cervix during first stage of labor in active phase among primipara women.

Kavanagh et al., (2005) conducted a study to assess the effect of breast stimulation on cervical ripening. One hundred patients who had completed 38 weeks' gestation and had uncomplicated antenatal courses were recruited and divided into two groups treatment and control. It was found that there was a significant change in the Bishop score of $3.96+/-1.34$ points in the stimulated group as compared with the control group $1.04+/-1.03$ points. After three days, a cross-over trial was performed with the treatment group becoming the control and the control group undergoing breast stimulation for the same period of time and under the same conditions. Again, the control group was found to have a better mean cervical score $(3.11+/-1.42$ points $)$ than the treatment group $(0.76+/-0.97$ points) during breast stimulation. Result suggested that no uterine hyper tonus was detected with gentle, unilateral breast stimulation, and there were no maternal or foetal complications as a result of this modality of cervical ripening.

\section{Limitations}

- The study was limited to the women's who are not present during the period of data collection.

- The study was limited to the less sample that is 30 control group and 30 experimental group.

- Limited time was available for data collection.

- The effectiveness of nipple stimulation in progress of labour among primipara women during first stage of labour will be determined through a single post-test.

\section{Conclusion}

Pregnancy is considered as a very precious event in every woman's life. It is filled with happiness, joy and surprises. It has been shown that the nipple stimulation plays a significance role in progress of labour and early effacement and dilatation of cervix. The results of the study signified that midwives can actively use nipple stimulation as a non-pharmacological method in progress of labour. Its indeed a simple procedure that can be practiced even by uneducated class of women and a natural way that can speed up labour process even when the mothers are in the labour room without support system.

\section{Conflict of Interest: None}

\section{References}

1. Benett V. Myles Text of Midwives. Churchill Living Stone, $14^{\text {th }}$ ed, London. 2003. Available from: https:// www.worldcat.org/title/myles-textbook-for-midwives/ oclc/52143613. 
2. Irene BM. Maternity Nursing. $5^{\text {th }}$ ed. Mosby Publication, Philadelphia. 1996.

3. Jensen IB. Maternal and Child Health Nursing. The C.V Mosby Company, $5^{\text {th }}$ ed., London. 1998.

4. AyaAGM, Vialles N, Mangin R et al. Chronobiology of labour pain perception: an observational study. British Journal of Anaesthesia 2004; 93(3): 451-453. Available from: https://academic.oup.com/bja/ article/93/3/451/290657 [PubMed/ Google Scholar].

5. Brown ST, Campbell US, Sharma PS. Characteristics of uterine contractions as two stages of cervical dilatation. American Journal of Obstetrics and Gynaecology 2005; 38: 77-79.

6. Razgaitis EJ. Nipple stimulation reduce the length of the labour. Non-pharmacological approach to the management of uterine contractions. Journal of Midwifery and Women's Health. 2010. Retrieved from http://www.winkipedia.org.

7. Qu Zhou P. Effectiveness of non-pharmacological approach to induce the cervical dilatation in the first stage of labour. 2007. http://www.eCAM advance access.

8. Physical and emotional impact on uterine contraction. Journal of Midwifery and Women's Health.

9. Qu, Zhou P. Effectiveness of non-pharmacological approach to induce the cervical dilatation in the first stage of labour. 2007. 